\title{
ILEGALISMOS URBANOS E A CIDADE
}

VERA DA Silva TELLES

\section{RESUMO}

Tomando como ponto de partida situações encontradas nas periferias paulistas, este artigo discute as relações redefinidas das relações entre o informal, o ilegal e o ilícito. Se é verdade que a transitividade entre o legal e ilegal, formal e informal sempre acompanhou a história de nossas cidades (e sociedade), apresenta-se hoje o desafio de construir um jogo de referência distinto do espaço conceitual que vigorava até recentemente, em grande medida regido pelo tema das chamadas incompletudes da modernidade brasileira.

PALAVRAS-CHAVE: Cidade; economia de bazar; mercados informais; ilegalismos.

\section{ABSTRACT}

Taking as a guideline situations found in the periphery of cities in the State of São Paulo, this article tries to redefine the notions of informal, illegal and illicit. If it is true that the interchange between legal and illegal, formal and informal has always been part of the history of our cities (and society), today the challenge is to build another kind of conceptual space, distant from the usual framework of the so-called incompleteness of Brazilian modernity.

KEYWORDS: City; Economy; informal markets; ilegalisms.

Doralice, 40 anos, mora em um bairro da periferia paulista com o marido, o filho e mais a mãe, um irmão e um sobrinho. Doralice é diarista. Ganhos parcos e irregulares, não mais do que três casas para cuidar da faxina. Provida de dotes culinários amplamente celebrados pela família, houve um tempo em que resolveu vender pão e broas que ela preparava durante o dia. Vendia à noite nas proximidades de um hospital em uma barraca improvisada na perua Kombi do marido. O empreendimento não deu muito certo e depois de alguns meses foi desativado. 
Mas Doralice é uma mulher batalhadora e não deixa escapar oportunidades para um ganho a mais para sua família.Assim, por exemplo, não hesita quando surge a oportunidade de montar uma banca de CDs piratas em um bairro próximo à sua casa. Um ponto de venda bastante modesto, mas que aciona redes de escalas variadas, a começar pelos garotos de uma favela ao lado, chamados para garantir a venda durante o dia, enquanto ela sai para o seu trabalho de diarista. Há também uma cascata confusa de intermediários que passa pela sociabilidade vicinal, mas que transborda amplamente o perímetro local: um parente próximo fez o contato com o agenciador dos CDs, um tipo obscuro que mantém relações obscuras com um "estúdio" obscuro em que os CDs são copiados e mais os agentes que empresariam esse negócio hoje amplamente expansivo e presente em qualquer ponto da cidade. Doralice não consegue reconstruir os percursos que os $\mathrm{CD}$ s percorrem até chegar a seu modesto ponto de venda - a partir de certo ponto o circuito fica, como se diz nos meios populares, "embaçado". Afinal, seguir os traços desse artefato não é tarefa fácil.A rigor isso definiria toda uma agenda de pesquisa que haveria de nos conduzir pelos fios da várias redes superpostas de que é feito o hoje redefinido mercado informal. Por ora basta dizer que são redes que passam pelo lado oficial, formal e cintilante da indústria cultural, que transbordam para os dispositivos sociotécnicos acionados nas fronteiras incertas do informal e ilegal, para se enredar nos múltiplos circuitos do comércio ambulante por onde circulam produtos de procedência conhecida, desconhecida, duvidosa ou ilícita, para então se condensar nas miríades de pontos de venda espalhados pela cidade. E aqui voltamos à Doralice.

Ela conhece muito bem as coisas da vida e sabe que não teria condições de bancar o seu negócio em algum lugar mais disputado e mais rendoso. Perguntamos a ela por que não um lugar mais rendoso já que ela teria acesso ao "fornecedor", acesso ademais garantido por relações de confiança, vínculos de proximidade e família. A resposta foi precisa: ela não teria "capital" para pagar fiscais ou então a polícia e muito menos para compensar as perdas na eventualidade de um "rapa". Enfim, Doralice é desprovida do cacife necessário para lidar com os representantes da ordem que parasitam os negócios infomaisilegais com a força da chantagem e da extorsão, definindo, em grande medida, os modos como esses mercados se organizam e se distribuem nos espaços urbanos ${ }^{1}$. Sendo assim, ela teve que se contentar com os ganhos irrisórios de uma banca pobre instalada em um lugar pobríssimo. Ganhos irrisórios e, além do mais, incertos, pois vez e outra ( $e$ muito freqüentemente) seus fornecedores ou intermediários desaparecem porque foram presos ou ficaram eles próprios devedores no perverso (e violento) mercado da proteção, ou então porque as relações de confiança foram, em algum momento e por razões as mais variadas
[1] Cf. Misse, Michel. Crime e violência no Brasil contemporâneo. Rio de Janeiro: Lumen Juris, 2006. 
(traições, disputas, deslealdades), rompidas em algum ponto dessa rede por onde se fazem as conexões entre as pontas mais pobres da cidade e os circuitos de uma riqueza cada vez mais globalizada. Aliás, foi por isso mesmo que ela desistiu do negócio.

Decididamente, Doralice estálonge de ser uma empreendedora. $\mathrm{O}$ que fazia não era mais do que um bico. Mais um entre tantos outros expedientes de que lança mão para lidar com as urgências da vida. Assim, por exemplo, ela não titubeia, nas horas do aperto, em mobilizar uma espantosa rede que opera o mercado de receitas médicas fraudadas para conseguir o remédio de que depende a vida do marido, e que passa por dentro das farmácias de maior porte da região, expediente, aliás, rendoso para os que inventam (balconistas e farmacêuticos de plantão, com a conivência de fiscais e outros) os artifícios para fazer da compra-e-venda dessas receitas um recurso a mais para complementar os baixíssimos salários pagos no mercado formal de trabalho. Doralice passou a ter uma tal familiaridade com esse mercado negro de receitas que ela própria, vez e outra, se transforma em uma intermediária, o que lhe rende uns trocados a mais cada vez que uma vizinha aflita (quase sempre mulheres, raramente homens) vem solicitar seus "conhecimentos" e "boas relações" para resolver um problema de urgência doméstica. Em outro momento qualquer e conforme as circunstâncias, Doralice não encontra nenhuma razão moral para recusar o "serviço" que lhe é proposto por um conhecido próximo e de confiança, e colocar a encomenda de "farinha" em sua bolsa, entrar em um ônibus, atravessar a cidade e tranqüilamente levar a mercadoria a seu destino, trazendo de volta um ganho modesto, mas que fará toda a diferença em um orçamento doméstico garantido no dia a dia, sem que por isso ela se considere comprometida com o "mundo do crime". Como ela diz, "não estou fazendo nada de errado, não roubo, não mato" - ela apenas está se virando como pode, como em tantas outras circunstâncias de sua vida.

Haveria mais a dizer sobre os percursos desta não muito pacata dona de casa.A rigor, há toda uma agenda de pesquisa que poderíamos definir a partir de uma situação como essa: seja seguir os produtos, os CDs pirata ou as receitas médicas fraudadas ou então a droga, para reconstituir, na medida do possível, a cadeia de conexões que define os circuitos por onde trafegam; seja fazer a etnografia dos agenciamentos práticos acionados nesses pontos de condensação de relações e mediações, tal como essa "história minúscula" permite entrever. Duas vias diferentes e complementares que certamente nos permitiriam prospectar os circuitos superpostos de um mundo urbano atravessado por expansiva trama de ilegalismos, novos e velhos, entrelaçados nas práticas urbanas, seus circuitos e redes sociais. Esse o ponto que interessa, por ora, reter. 
O fato é que, hoje, a vida social parece atravessada por um universo crescente de ilegalismos que passam pelos circuitos da expansiva economia (e cidade) informal, o comércio de bens ilegais e o tráfico de drogas (e seus fluxos globalizados), com suas sabidas (e mal conhecidas) capilaridades nas redes sociais e nas práticas urbanas. É nesse ponto que a história de Doralice interessa. Trata-se de um jogo situado de escalas que se superpõem e se entrelaçam nas "mobilidades laterais", para avançar uma discussão a ser feita nas páginas seguintes desse personagem urbano, cada vez mais comum em nossas cidades, que transita nas fronteiras borradas entre o informal e o ilegal ao longo de percursos descontínuos entre o trabalho incerto e os expedientes de sobrevivência mobilizados conforme o momento e as circunstâncias.

É sempre possível dizer que nada disso é novidade, apenas repõeo que sempre esteve presenteem nossas cidades. No entanto, pouco entenderemos do quevem acontecendo se nos mantivermos presos a um marco descritivo-analítico pautado pelas mazelas de uma modernidade incompleta. Tampouco entenderemos o que se passa se tomarmos situações como essas aqui descritas apenas e tão-somente como caso exemplar da "viração" própria das desde sempre conhecidas situações de pobreza. Na verdade, poderíamos multiplicar os exemplos (voltaremos a eles ao final) e, a partir de cada situação, tal como "postos de observação", apreender os perfis de um mundo urbano alterado e redefinido pelas formas contemporâneas de produção e circulação de riquezas, que ativam os diversos circuitos da dita economia informal, que mobilizam o "trabalho sem forma", para usar a expressão de Chico de Oliveira, e se processam nas fronteiras incertas do informal, do ilegal e também do ilícito². É esse o plano de atualidade, no qual se inscreve os percursos incertos de personagens urbanos como o aqui descrito. E cifra de contemporaneidade, pois entra em ressonância com o que vem acontecendo em outros lugares, também nas cidades dos chamados países do Norte.

O fato é que as relações incertas entre o lícito, o ilegal e o ilícito constituem um fenômeno transversal na experiência contemporânea. São vários os autores que vem chamando a atenção para essa transitividade entre o informal, o ilegal e o ilícito, com uma preocupação, mais ou menos explicitada, em distinguir a natureza da transgressão que se opera no âmbito da economia informal ou então a que define as atividades ilícitas ou criminosas, como o tráfico de drogas, armas e seres humanos3.

Bem sabemos que essa transitividade acompanha a história de nossas cidades, já foi cantada em prosa e verso e tematizada por uma já longa e prestigiosa literatura, para não falar das circunstâncias históricas que presidiram o desde sempre expansivo mercado informal. Mas também é verdade que nos vemos hoje em face do desafio de construir
[2] A redefinição das relações entre o formal e o informal no capitalismo contemporâneo e, mais particularmente, olugar redefinido do informal sob a lógica de um processo de acumulação que exige, mobiliza e aciona a sua reprodução ampliada está hoje no centro de um debate que já conta com uma importante literatura de referência. Para efeito desse artigo, vale citar Portes, A., Castells, M.e Benton, L.A.(orgs.). Informal economy: studies in advanced and less developed countries. Baltimore: Jonhs Hopkings University Press, 1989.

[3] Essa équestãocentral de um projeto em curso, realizado em parceria com pesquisadores da Universidade de Toulouse Le Mirail (Acordo CapesCofecub). Esse texto beneficia-se em larga medida dessa cooperação francobrasileira.É, sobretudo, devedor da interlocução com Angelina Peralva com quem partilho a coordenação desse projeto. Textos e documentos de referência estão disponíveis em «www.fflch.usp.br/sociologia/pos-graduacao/ sites/trajetorias/index.htm>. 
[4] Retomo aqui e desdobro em outras direções questões tratadas em artigo escrito em co-autoria com Daniel Hirata. Cf. Telles, Vera S. e Hirata, Daniel. "Cidade e práticas urbanas: nas fronteiras incertas entre o ilegal, o informal e o ilícito". Estudos Avançados da USP, vol. 21, no 61, 2007, pp. 173-192.

[5] Ruggiero, Vincenzo e South, Nigel. "The late city as a bazaar: drug markets, illegal enterprise and the barricades". The British Journal of Sociology, vol. 48, $\mathrm{n}^{\circ}$ 1, 1997, pp. 54-70. um espaço conceitual distinto do que vigorava até recentemente e pelo qual a discussão se processava sob o ângulo das chamadas incompletudes da modernidade brasileira. Será preciso trazer a situação brasileira para outro prisma de referências. Essa é a preocupação que subjaz a esse texto. Não se trata de fazer um balanço bibliográfico, tampouco rastrear teorias e questões polêmicas, muito menos oferecer explicações ou marcos conceituais alternativos. Isso exigiria muito mais do que é possível fazer no escopo deste artigo. Arriscaria dizer que se trata não mais do que um exercício, talvez uma experimentação a partir das pistas que os autores comentados nos fornecem em suas pesquisas, e são essas que interessam, na medida em que oferecem um repertório ampliado de referências pertinentes ao cenário contemporâneo.

\section{NAS FRONTEIRAS INCERTAS DO INFORMAL, ILEGAL E ILÍCITO ${ }^{4}$}

Em artigo de 1997, Ruggiero e South lançaram mão da metáfora do bazar - a cidade como bazar - para descrever as intersecções entre os mercados formais e os mercados informais, ilegais ou ilícitos, tal como se configuraram, a partir dos anos de 1980, nas metrópoles dos países centrais do capitalismo contemporâneo5. Com evidente intenção polêmica, a metáfora evoca a alteridade nos traços de "orientalismo" associados ao bazar, para chamar a atenção que ele, agora, se encontra incrustado no núcleo das modernas (e ocidentais) economias urbanas. Na mira dos autores, está um cenário urbano no qual se expande uma ampla zona cinzenta que torna incertas e indeterminadas as diferenças entre trabalho precário, emprego temporário, expedientes de sobrevivência e atividades ilegais ou delituosas. Nas fronteiras porosas entre o legal e o ilegal, o formal e informal, transitam as figuras contemporâneas do trabalhador urbano, lançando mão, de forma descontínua e intermitente, das oportunidades legais e ilegais que coexistem e se superpõem nos mercados de trabalho. "Mobilidades laterais", definem os autores, de trabalhadores que oscilam entre empregos mal pagos e atividades ilícitas, entre o desemprego e o pequeno tráfico de rua, negociando a cada situação e em cada contex to os critérios de aceitabilidade moral de suas escolhas. É isso propriamente que caracteriza o bazar metropolitano: a intersecção entre os mercados irregulares e os mercados ilegais, esse embaralhamento do legal e do ilegal, e o permanente deslocamento de suas fronteiras.

O "bazar metropolitano", dizem os autores, começou a ganhar forma em meados da década de 1980 . No caso da Inglaterra e dos Estados Unidos, o momento da virada conservadora de governos que fizeram por desmanchar direitos e garantias sociais foi o ponto de arranque da precarização do trabalho e a redefinição dos mercados urbanos de trabalho. Em termos gerais, anos de reestruturação produ- 
tiva e da chamada flexibilização das relações de trabalho que terminou por esfumaçar as diferenças entre trabalho, desemprego e expedientes de sobrevivência, na própria medida em que o assim chamado informal instala-se no núcleo dinâmico dos processos produtivos e, no mesmo passo, seexpande pelas vias de redes de subcontrataçãoeformas diversas de mobilização do trabalho precário, sempre nos limites incertos entre o legal, o ilegal, também entre o ilícito e delituoso, quando isso envolveo tráfico de seres humanos direcionado para as miríades de oficinas clandestinas que se espalham nesses circuitos produtivos ${ }^{6}$.

Esses foram também anos em que as atividades ilícitas mudaram de escala, se internacionalizaram e se reorganizaram sob formas polarizadas entre, de um lado, os empresários do ilícito, em particular do tráfico de drogas e que, a cada local irão se conectar com a criminalidade urbana comum, e, de outro, os pequenos vendedores de rua, que operam nas margens da economia da droga e transitam o tempo todo entre a rua e a prisão. Esses são os "trabalhadores precários" da droga, que se multiplicam na medida em que o varejo se expande e se enreda nas dinâmicas urbanas: modulação criminosa do capitalismo pós-fordista,criminalidadejust-in-time, define Ruggiero, que responde à variabilidade, às oscilações e às diferentes territorialidades dos mercados. É nesse sentido que as atividades ilícitas, não apenas o tráfico de drogas, passam a compor as economias urbanas nos pontos de intersecção com os expansivos mercados irregulares, multiplicando as oportunidades para a circulação de bens e produtos de origem duvidosa, eque são transacionados no jogo multiforme das interações sociais independentemente de serem legais ou ilegais, ou de origem ilícita.

Por certo, as questões propostas pelos autores estão longe de dar conta de uma problemática hoje tratada por uma vastíssima literatura sobre a economia da droga em suas várias dimensões, escalas e formas de territorialização. Mas não é bem esse o ponto que interessa aqui discutir. O que importa, isso sim, é reter o plano em que os autores apresentam suas questões, colocando a cidade - o bazar metropolitano - como plano de referência para situar os mercados ilegais em suas interações com as dinâmicas urbanas. É justamente isso que, assim parece, fez a fortuna desse texto nos debates recentes.

\section{FORMAS CONTEMPORÂNEAS dE PRODUÇÃO E CIRCULAÇÃO dE RIQUEZAS}

A noção hoje revisitada7 de "economia de bazar" circula entre pesquisadores às voltas com processos próximos às situações descritas por Ruggiero e South. É isso justamente que sugere o interesse da metáfora do bazar para a descrição das cidades contemporâneas, oferecendo um prisma que coloca a cidade como plano de referência para a descrição dos processos em curso. E é isso o
[6] Ruggiero. Crime and makets: essays in anti-criminology. Oxford: Oxford University Press, 2000.
[7] A referência a Clifford Geertz é passagem quase obrigatória pelos autores que lançam mão atualmente da noção de "economia de bazar". Cf. Geertz,Cliffort. "Thebazaareconomy in Cefrou". In: Geertz, C., Geertz, H. e Rosen, L. (eds.). Meaning and social order in Moroccan society. Cambridge: Cambridge University Press, 1979. 
[8] Cf. Kokoreff, Michel. “Trafics de drogue et criminaliteé organisée: une relation complexe". Criminologie, vol. 7, $\mathrm{n}^{\circ}{ }_{1,2004}$, pp. 9-32; Idem. "Faire du business dans les quartiers: elements sur les transformations socio-historiques de l'economie des stupefiants en milieux populaires". Déviance et Société, vol. 24, n 4 , 2000, pp. 40324; Duprez, Dominique e Kokoreff, Michel. Les mondes de la drogue. Paris: Éditions Odile Jacob, 2000; Godefroy, Thierry. "Économies parallèle ou métissées? Exemples d'activités hybrides". In: Bessette, Jean-Michel (org.). Crimes et cultures. Paris, L'Harmattan, 1999, pp. 159-174.

[9] Palidda, Savatore. "Milanglobal: entre affairisme et politiques securitaires". In: Peraldi, Michel (org.). $\mathrm{La}$ fin des norias? Réseaux migrants dans les économies marchandes en Méditerranée. Paris: Maisonneuve \& Larose, 2002.

[10] Peraldi, Michel (org). Cabas et containers: activites marchandes informelles et reseaux migrants transfrontailiers. Marseille: Maisonneuve et Larose, 2002; Idem. "Marseille: reseaux migrants transfrontailiers, place marchant et economie de bazar". Culture E Politique, $\mathrm{n}^{\circ}$ 33-34, 1999, pp. 51-67. que permite colocar em perspectiva (e em diálogo) pesquisas que tratam dos vários circuitos e redes de extensão variada que conformam o que se convencionou chamar de economias subterrâneas nas periferias francesas, na superposição das atividades informais e nos mercados de rua, nos quais os fluxos de dinheiro, mercadorias, bens de origem ilícita e também drogas se entrecruzam em um complexo sistema de trocas, se inscrevem no jogo das relações sociais e passam a compor as dinâmicas urbanas que transbordam amplamente o perímetro estreito dos chamados quartiers sensibles ${ }^{8}$. Ou então, a "segunda grande transformação", para usar os termos de Palidda, que atinge, por exemplo, os núcleos industriais italianos, transfigurando a moderna e desenvolvida cidade de Milão, agora atravessada por toda sorte de ilegalismos em que se articulam a migração clandestina, a ampla circulação de produtos da contravenção, do contrabando e da pirataria, vindos sobretudo do sudeste asiático (mas não só) e a nebulosa de relações entre o ilegal, o informal e o ilícito, que acompanham os processos de terceirização produtiva ou deslocalização das plantas industriais9.

Por outro lado, as pesquisas que tratam do que vem sendo chamado de novas formas migratórias lançam luz sobre um outro vetor de constituição da "economia de bazar", nas trilhas de outras dimensões das reconfigurações do capitalismo contemporâneo. No contexto francês, Michel Peraldi faz uso dessa noção, com referência ao texto de Ruggiero e South, para tratar das dinâmicas urbanas hoje redefinidas sob o impacto de formas de circulação de bens e riquezas que seguem os amplos circuitos da migração por onde se estruturam redes transnacionais de um proliferante comércio ambulante ${ }^{10}$. São redes que atravessam fronteiras, articulam centros comerciais espalhados em vários pontos do planeta e se territorializam sob as diversas modulações do chamado mercado informal em expansão nos centros urbanos do primeiro mundo, em particular nas cidades de fronteira, situadas nos pontos de conexão entreesses vários circuitos, muitas delas ponto de chegada de vagas migratórias anteriores e que agora se redefinem nessa cartografia mutante do mundo contemporâneo.

Os circuitos por onde circulam os produtos até chegar aos mercados populares nos centros urbanos fazem o traçado de verdadeiras redes transnacionais de trocas informais nas fronteiras porosas do legale ilegal, sempre tangenciando os mercados ilícitos (drogas, armas, seres humanos). Ao lado do que se poderia chamar de migração da miséria (a tragédia dos clandestinos sobre os quais tanto se fala), observam-se novas formas migratórias que não visam à instalação nos países de destino, colocando em movimento homens e mulheres que circulam entre países e regiões conforme as circunstâncias e oportunidades de trocas e comércio: as "formigas da mundialização" ou "novos nômades 
da economia subterrânea", diz Tarrius ${ }^{11}$; pequenos comerciantes que praticam o que Peraldi chama de commerce à la valise (quer dizer: os nosso conhecidos "sacoleiros"), envolvidos em dispositivos comerciais transnacionais que articulam produtores do Norte e consumidores do Sul ${ }^{12}$. Alguns, ou melhor, multidões deles são independentes, outros operam sob a encomenda de comerciantes bem estabelecidos nos entrepostos comerciais, algo como atacadistas que mobilizam as "formigas" para o abastecimento dos produtos que serão, depois, negociados em outros tantos locais ${ }^{13}$. Populações itinerantes que operam em redes mais ou menos extensas, seguindo "os territórios circulatórios"14 tecidos por laços familiares e de proximidade (núcleos sedentarizados das vagas migratórias anteriores), ancoradas nas várias cidades e localidades por onde passam pessoas e produtos ${ }^{15}$.

São esses circuitos transnacionais de migração que permitem a circulação de bens e mercadorias que, sem esses novos migrantes, não chegariam aos mercados populares do Norte ou do Sul. Esta é a tese defendida por Alain Tarrius: os grandes atores econômicos da mundialização mobilizam os pobres como consumidores, como clientes e também como passadores, fora das regras oficiais e ao largo das convenções comerciais, fazendo os produtos chegarem aos países pobres e às populações pobres dos países ricos.Assim, produtos eletrônicos (filmadoras, computadores portáteis, mp3, aparelhos de DVDs etc.) despejados aos milhares em Dubai, espalham-se pelo Leste europeu e chegam até as periferias alemãs ou francesas graças às coortes de afegãos, iranianos, georgianos e mais todos os "derrotados das guerras" que dizimaram os países caucasianos nos últimos tempos. Esses "novos nômades", populações "em excesso", seguem as redes sociais construídas nas trilhas das diásporas anteriores ou recentes ${ }^{16}$ e são portadores de competências circulatórias (quer dizer, saber passar pelas fronteiras, contornar as restrições, os controles e as fiscalizações), transformando-se em atores de amplas transferências internacionais de mercadorias. Essa competência circulatória, sugere Tarrius, ajusta-se ao "projeto de uma mundialização selvagem, porque ultra-liberal", quer dizer, "fazer chegar aos mínimos recantos solváveis do planeta, mercadorias de que esses lugares seriam privados em função das oscilações aleatórias das políticas nacionais":

[...] eis, a titulo de exemplo, as peregrinações de uma câmara de vídeo, de concepção nova - grava diretamente no DVD - dotada de boas lentes, e que apareceu no mercado mundial em 2005 . Em dezembro desse ano, eram vendidas por 420 euros em Dubai e no Kowait, onde chegavam massivamente, como 'destino final', enquanto os distribuidores franceses, alemães e espanhóis as comercializavam por um preço em torno de 1400 euros. Depois de uma passagem furtiva pelas fronteiras dos emirados, graças às coortes de migrantes afegãos, iranianos, caucasianos etc., esses aparelhos eram reven-
[11] Cf.Tarrius, Alain.La mondialisation parle bas: les nouveaux nomades de l'economie souterraine. Paris: Balland, 2002.

[12] Cf. Peraldi. "Aventuriers du nouveau capitalisme marchand:essai d'anthropologie de l'éthique mercantil". In: Adelkhah, Fariba e Bayart, Jean-François (orgs.). Voyage du développement:émigration, commerce et exil. Paris: Karthala, 2007.

[13] Por exemplo, sírios búlgaros que passam as encomendas para os afegãos, deixando a estes todos os riscos das passagens pelas fronteiras nos circuitos que articulam Dubai e o Leste europeu, passando por Istambul. Cf. Tarrius. La remontée des Suds: afghans et marocains en Europe Méridionale. Paris: L'Aube, 2007.

[14] “Território circulatório" é termo cunhado por Alain Tarrius para se referir às tramas relacionais engendradas pelos e nos circuitos transnacionais dessas populações itinerantes.

[15] Essas novas formas migratórias é matéria de uma já vasta bibliografia fundada em pesquisas que seguem os circuitos dessa itinerância globalizada. Além dos textos já citados, cf. Cesari, Jocelyne (dir.). La Méditerranée des réseaux: marchands, entrepeneurs et migrants entrel'Europe et le Maghreb. Paris: Maisonneuve \& Lorose, 2002; Dimenescu, Dana. "Le migrant connecté: pour un manifeste épistémologique". Migration/Societé, vol. 17, $\mathrm{n}^{\circ}$ 102, pp. 275-292, disponível em <www.ticm.msh-paris.fr〉; Portes. "La mondialisation par le bas". Actes de la Recherche en Sciences Sociales, $\mathrm{n}^{\circ} 129$, set., 1999.

[16] Há algo como uma geopolítica plasmada na cartografia dessas itinerâncias que remete às turbulências que devastaram essas regiões ao longo das últimas décadas, ao lado das restrições cada vez mais ferozes nas fronteiras européias. 
[17] Tarrius. La remontée des Suds, op. cit., p.10. didos porvolta de 440 euros em Beirute e em Istambul, e 430 euros em Sofia [...]. Iremos reencontrar essa mesma câmara, por 460 euros, nas periferias francesas, tendo lá aparecido, como se diz, "caídas do caminhão" [tombé du camion], mas que passaram pela Alemanha por intermédio dos turcos que, por sua vez, as receberam dos afegãos e dos azeris, que seguiram os itinerários que passam por Dubai. Quanto aos fabricantes, eles respeitaram estritamente os acordos do comércio internacional, entregando, como "destino final", centenas de milhares de aparelhos em um Estado que conta com apenas alguns milhares de cidadãos ${ }^{17}$.

Éde se notar, ainda comenta o autor, o aparente paradoxo de formas de contrabando (é disso que se trata) próprias do mundo pré-capitalista e que são agora mobilizadas a serviço da forma contemporânea do capitalismo. São formas variadas de contrabando, mobilizando as "formigas da mundialização", e a elas se deve ainda acrescentar práticas da falsificação e da pirataria que se generalizam por todos os lados, muitas vezes com a conivência ou o incentivo das próprias empresas interessadas em colocar em circulação o "nome da marca", ampliando ainda mais seus mercados nessa espécie de fronteira de expansão do capital que são os "pobres" e seus hoje proliferantes mercados de consumo, no Norte e no Sul, à Leste e a Oeste do planeta. Sob esta lógica, diz ainda Tarrius, em uma observação carregada de conseqüências, os migrantes passam da anterior submissão ao lugar-cidade, à submissão às lógicas comerciais apátridas das grandes empresas mundiais. Por certo, "a exploração não é menos sórdida, mas as modalidades de autonomização do migrante são outras".

[...] a mobilização dos pobres para passar, para contornar normas e regras, produz novas formas de migração, povoadas por esses pequenos atores transnacionais. Esses migrantes generalizam mobilidades de formigas que se amplificam, em vez de se esgotar na sempiterna concentração de populações em torno das diversas zonas de atividade industrial, agrícola ou de serviços, campos da miséria. Eles são, ademais, excedentes em relação aos limites das nações por onde atravessam, estão fora do raio de ação das políticas ditas de integração e de igualdade de oportunidades para os recém-chegados, generosas mas pouco eficientes já há várias décadas para inúmeros estrangeiros. Minoritários, certamente, mas notáveis atores das circulações transnacionais, mantendo os vínculos com seus locais e meios de origem, se organizando em redes já mundializadas, eles produzem uma nova forma migratória carregada de sentido para o conjunto das populações e dos Estados ${ }^{18}$.

Se, como sugere Ruggiero, o "bazar metropolitano" se constituiu nas trilhas das mutações do trabalho e da implosão das formas reguladas do emprego, vemos aqui um outro lado, em sintonia com o 
primeiro, modulações de um mesmo processo de reconfigurações do capitalismo contemporâneo: modos de circulação de bens e riqueza que ganham forma nessa espécie de comércio globalizado de "sacoleiros" nos territórios circulatórios pelos quais os novos migrantes fazem sua itinerância entre fronteiras e países e que se territorializam nos mercados populares e no comércio de rua hoje em expansão nos centros urbanos dos países do Norte e do Sul.

Essa é questão também tratada por Michel Peraldi ao estudar os mercados populares que se constituíram no mediterrâneo francês (Marseille, sobretudo). Atento aos circuitos de bens e pessoas (entre países do Magreb e da Europa) que lá deságuam e, em suas pesquisas mais recentes, seguindo outros percursos e outros mercados que ganharam forma na própria medida da endurecimento das restrições nas fronteiras francesas ${ }^{19}$, Peraldi reforça a hipótese de uma circulação ampla de mercadorias que se viabiliza em função dessas populações circulantes. Versões contemporâneas de uma espécie de capitalismo mercantil, talvez, diz ele, um "capitalismo de párias" (Weber), agora conectado aos movimentos superacelerados de valorização do chamado capitalismo flexível (e as cascatas transnacionais de subcontratações) sob a égide do capital financeiro e que coloca em circulação volumes inimagináveis de modelos, marcas, tipos evariações de estilo, tudo em rapidíssima rotação e ciclos cada vez mais curtos de obsolescência de produtos mal saídos dos espaços produtivos, que vão se substituindo uns aos outros conforme mudam as preferências, os públicos-alvos, o jogo feroz das concorrências e as disputas de mercados. É esse capitalismo perdulário e predatório que ativa tal comércio circulante. É desse formidável desperdício que esse comércio circulante se alimenta. Na análise de Peraldi, são três as funções desses mercados, entre a itinerância desses comerciantes circulantes e seus modos de territorialização nos centros urbanos: capturar produtos destinados a outros mercados, dando-lhes outras destinações improváveis pelas vias oficiais dos mercados; relançar todos os invendidos (estoques de falência, produtos com defeito, erros de programação etc.), drenando esses produtos conforme lógicas de preferência e de usos locais, que o mercado mundial ignora ou não pode atingir; por fim, reativar o ciclo interrompido de mercadorias postas fora de circulação nas condições modais do mercado mundial, as chamadas "pontas de estoque" que são relançadas, transformadas e adaptadas aos mercados nos quais passarão a circular ${ }^{20}$.

Essas redes transnacionais por onde circulam produtos e pessoas criam condições para a circulação de produtos que, em outras situações, não chegariam a esses mercados: embargos, interditos, controles que marcam as fronteiras, diferenciais de renda e riquezas que tornam difícil quando não impossível o acesso a esses bens e mercadorias. Em
[19] Nos últimos anos, também Istambul ou Dubai e de lá outras rotas em direção ao Leste, da Ásia Central ao Sudeste asiático. Em todas essas rotas, perfila-se um tramado de mercados populares, acompanhados de um proliferante comércio de rua, fazendo circular produtos quase sempre de origem duvidosa (contrabando, falsificações, fraude, pirataria). Esses mercados pontilham os centros urbanos nos chamados países do Sul, inclusive os pobres e combalidos Estados africanos, passando pelos também pobres e também combalidos países do Leste europeu ou da região do Cáucaso. A propósito, ver os vários artigos que compõem a coletânea organizada por Adelkhah e Bayart, op. cit. Quanto à América Latina, há evidências de que processos semelhantes vêm ocorrendo.

[20] Peraldi, "Aventuriers du nouveau capitalisme marchand", op. cit. 
[21] Peraldi, "Marseille: réseaux migrants transfrontaliers, place marchande et économie de bazar", op. cit.,p.56.Como diz Peraldi, e também Tarrius, não haveria mercado nem relações mercantis sem um dispositivo de cafés, bares, restaurantes, casas noturnas ou de jogos, oficiais ou clandestinos, por onde as informações circulam, por onde são tecidos os engajamentos recíprocos, os acordos informais, as redes de confiança e os jogos de reciprocidades. outros termos: tais mercados alimentam-se de obstáculos, interditos e proibições que vigoram para a circulação de mercadorias entre países, além das normas e das legislações que codificam os regimes de circulação em cada país. Mas é justamente aí que não só se qualifica a competência desses pequenos comerciantes, mas também se especifica o sentido do "bazar contemporâneo", tal como proposto por Peraldi: não tanto a oralidade (acordos informais, regras de confiança, força da palavra dada) e as tramas relacionais que os caracterizam, mas a capacidade de ultrapassar e contornar as fronteiras e as diferenças que demarcam (e obstam) a circulação entre países. Toda uma trama relacional é acionada e toda uma competência circulatória é ativada justamente nas dobras do legal e do ilegal, nas dobras das fronteiras políticas e desses territórios circulatórios que as transpassam o tempo todo: suborno nas alfândegas, documentos falsos, negócios escusos com fiscais e policiais, trocas de influência, compra de proteção, acertos com condutores de caminhões etc. É nesse sentido que Peraldi faz uso da noção de "economia de bazar": um dispositivo comercial que coloca em cena comerciantes estabelecidos em seus postos, vendedores ambulantes, "sacoleiros", consumidores e mais a trama de relações que passam por essa teia de intermediários e mediações, pelas quais os agenciamentos são feitos nas dobras do legal e ilegal, do formal e informal. A cada ponto dessa trama que viabiliza a circulação de mercadorias, esses atores estão em situações relacionais, convocados a negociar constantemente a "aceitabilidade moral de seus comportamentos" em uma situação "que torna possível a coexistência da legalidade e da ilegalidade, e a mudança permanente dos seus limites" nos termos de "negociações, sempre situadas, nas cenas públicas ou privadas condicionadas pelas trocas mercantis" 21 .

$$
\star * \star
$$

Vale dizer que na mira desses autores está, na verdade, um ponto crítico que pauta em grande medida as questões postas em discussão. Eles propõem um campo de discussão que desativa essa espécie de amálgama confuso (e nada inocente) que associa migração, miséria, terrorismo islâmico, fundamentalismo religioso, tráfico ilícito e "crime organizado", acionando as obsessões securitárias, as políticas repressivas e a legislação de exceção que vêm se multiplicando no cenário europeu. Ao seguir as pistas dessas itinerâncias de bens e pessoas, eles colocam em evidência os mundos sociais que se desenham nos "territórios circulatórios" por onde transitam essas populações com base em uma densa trama relacional, contraponto empírico e crítico aos cenários de miséria e degradação associados ao tráfico de seres humanos e de legiões de clandestinos mobilizados pelas redes 
de subcontratação e trabalho precário. Essas pesquisas terminam por traçar um outra cartografia do mundo e da mundialização, e oferecem, por isso mesmo, um outro jogo de referências para propor as questões pertinentes ao cenário contemporâneo ${ }^{22}$.

Muito mais poderia ser dito a respeito dessas pesquisas. Por ora, vale reter algumas questões que ajudam a requalificar o "bazar contemporâneo" que foi nosso ponto de partida.

Primeiro: se há porosidade nas fronteiras do legal-ilegal, do formal-informal, também é verdade que a passagem não é simples. Como parece evidente nos comentários acima, é justamente nessas dobras que se dão os agenciamentos políticos próprios aos mercados de proteção e às práticas de extorsão (fiscais, polícia, agentes políticos, agentes locais dos poderes públicos etc.) em suas várias modulações conforme circunstâncias de tempo e espaço, que também variam conforme se alteram as condições políticas, os rigores repressivos e os critérios de incriminação de bens e produtos em circulação23. Esse fato permite situar em escala ampliada uma questão que Michel Misse já propôs há bastante tempo e sempre volta a insistir como central para o entendimento das dinâmicas urbanas próprias aos mercados informais e ilegais nas cidades brasileiras. Em outros termos: nessa espécie de economia política dos ilegalismos urbanos, os mercados de proteção (e práticas de extorsão) compõem a face política do "bazar contemporâneo". Como afirma Misse, o mercado de proteção (com suas conhecidas seqüelas violentas) é constitutivo das formas de regulação dos mercados informais e ilegais ${ }^{24}$. Pois, então, fica a sugestão de que, hoje, essa é uma questão central nos modos de funcionamento do capitalismo contemporâneo. Peraldi propõe uma ousada (e interessante) hipótese de que é justamente nesse ponto que vem se dando a apropriação privada dessa riqueza circulante em escala transnacional, envolvendo esses "representantes da ordem" responsáveis pelo controle das fronteiras e suas passagens. Embora seja longo o trecho, vale a pena citar:

Ocontrabando e as circulações transnacionais de mercadorias não podem se efetuarsem o envolvimento o o apoio diretos dos funcionários do Estado, sobretudo os aduaneiros, que permitem "comprar as rotas" [acheter la route] conforme uma expressão usual em Tanger. Osigno mais tangível da regularidade dos lucros do commerce à la valise e de outras formas de contrabando pode ser averiguado diretamente no luxo ostensivo das "vilas" que os aduaneiros argelinos construiram nos bairros ricos de Oran, Tanger ou La Marsa. [...] Esses beneficiários do comércio transnacional podem ser encontrados, agora, ao lado das classes médias dos países emergentes, nos mesmos bairros em que moram, nas portas das escolas privadas em que seus filhos estudam, nas mesmas estações balneárias onde passam as férias,
[22] Essa operação crítica é questão discutida em Tarrius. Les nouveaux cosmopolitisme. Paris: L'Aube, 2000.

[23] Cf. Tarrius. "Au-delà des Etatsnations: societés, cultures et réseaux de migrants en Mediterranée occidentale". In: Peraldi (org.). La fin des norias?, op. cit.

[24] Cf. Misse, op.cit. 
[25] Peraldi, "Aventuriers du nouveau capitalisme marchand", op.cit., p.109.

[26] Cf.AdelkhaheBayart. "Introdution". In: Adelkhah e Bayart, op. cit.; Cuttita, Paolo. "Le monde-frontière: le contrôle de l'immigration dans l'espace globalisé". Culture $\mathcal{E}$ Conflits, $n^{\circ} 68$, pp. 61-84, 2008.

[27] Sassem, Saskia. Globalisation and its discontents: essays on the new mobility and money. Nova York: The New Press, 1998.

[28] Ramoneda, Josep. "Archipel de l'exception". Culture $\mathcal{E}$ Conflits, $\mathrm{n}^{\circ} 68$, 2008, pp.13-16. com a particularidade de terem sido formados na dobras do capitalismo mercantil e também das economias rentistas. [...] essas categorias sociais são economicamente estéreis, na medida em que seus modos de enriquecimento, por mais espetaculares que sejam, raramente constituem um princípio de acumulação primitiva capitalista convertida em alguma forma de investimento produtivo [...]. Porém, em geral, suas despesas suntuárias ou estatutárias notadamente sob lógicas patrimoniais (filhos, casa, aquisições imobiliárias) abremespaço para as lógicas especulativas das quaissão mais vitimas do que beneficiárias, deixando o campo livre para a constituição de um capitalismo deslocalizado em campos que eles próprios abriram.A emergência de um capitalismo chinês transnacional nesses terrenos é, hoje, a manifestação mais visível e mais unificada da qual será necessário ainda fazer a história e o inventário 25 .

Expedientes crapulosos, diz Peraldi, que se alimentam de todos os controles e interdições que pesam sobre essas populações circulantes. Mas são esses mesmos interditos, importante também dizer, que ativam a agenda securitária e as políticas de exceção no cenário europeu, desdobrando-se na redefinição contínua das formas de controlee suas modalidades operatórias ${ }^{26}$. Em outros termos, se as migrações, como bem nota Sassen, é constitutiva da história do capitalismo ${ }^{27}$ e é hoje um vetor poderosíssimo dos modos de circulação de riquezas, não é possível deixar de considerar os expedientes que se fazem justamente nas fronteiras-passagens, bem como os deslocamentos e as redefinições que se processam em função desses agenciamentos político-repressivos, com impactos consideráveis nas regiões de passagem: conflitos, turbulências, violências, controles mafiosos e, sobretudo, o que um autor chamou de "arquipélagos da exceção" que redesenham a cartografia do mundo contemporâneo ${ }^{28}$.

Se há porosidade nos âmbitos formal-informal, legal-ilegal, lícitoilícito, isso não quer dizer indiferenciação entre uns e outros, pois é justamente nas suas dobras que se dão os agenciamentos políticos (corrupção, extorsão, repressão, violência e as várias modulações dos mercados de proteção, entre outros) que condicionam essa ampla circulação de bens, mercadorias, pessoas e populações itinerantes. Em outros termos, ao contrário do que muitas vezes sugere a metáfora dos fluxos e dos circuitos, os espaços não são lisos, e são justamente suas asperezas, digamos assim, que interessa averiguar; é justamente aí quevai se constelando a face política do "bazar contemporâneo". Por outro lado e ao mesmo tempo, as pesquisas aqui comentadas sugerem que é também nessas dobras que se circunscrevem campos de gravitação, para lembrar outra metáfora, dessa vez vinda de Thompson, o historiador, de experiências regidas por uma espécie de "arte do contornamento" que a competência circulatória descrita pelos autores de 
alguma forma expressa, mas que também poderíamos (e podemos) identificar como um traço transversal da experiência contemporânea, bastante evidente, aliás, no âmbito de nossas cidades ${ }^{29}$.

Segundo: o tráfico de drogas está presente e também compõe este amplo circuito transnacional de circulação de bens, mercadorias e pessoas. Não é o caso, nos limites desse texto, de se deter nas circunstâncias que, sobretudo no correr dos anos de 1990, fizeram desses tráficos uma proliferante e muitíssima rendosa atividade com impactos consideráveis nas dinâmicas (e economias) urbanas nas cidades e regiões por onde passam e se enraízam. Por enquanto, basta dizer que as redes transnacionais da economia da droga mudaram de escala e amplitude no correr desses anos. São outras modulações dos mesmos processos que ativaram as migrações transnacionais das últimas décadas ${ }^{\circ}$, ganhando configurações particulares conforme as circunstâncias geopolíticas (mutantes e turbulentas) das regiões produtoras e de passagem ${ }^{31}$. Estruturam-se como verdadeiras economias que se beneficiam das mutações recentes do capitalismo contemporâneo (produção flexível, financeirização da economia, tecnologias digitais) nas condições de ultraliberalismo e enfraquecimento das regulações estatai ${ }^{32}$. Vale notar: se é verdade que os circuitos e as redes do comércio circulante transnacional tangenciam e por vezes, sob circunstâncias locais, se articulam com os tráficos ilícitos, essas redes não se confundem. Tarrius mostra, sobretudo em suas pesquisas mais recentes (nas rotas do Leste europeu), que não são as mesmas redes nem os mesmos agenciamentos locais. As conexões, os comprometimentos e os modos de regulação (controles mafiosos e violentos no caso das drogas) são outros, as rotas (com seus pontos/locais de passagem) também elas não são as mesmas, apesar de sua proximidade nas vastas regiões, ao Sul e ao Leste, por onde passam.

No entanto, a questão se coloca de outro modo quando vista sob o ângulo das dinâmicas e economias urbanas das regiões em que a economia da droga se instala e se ramifica: seja seus impactos nos mercados urbanos de trabalho e a questão das "mobilidades laterais" de que fala Ruggiero e South 33; seja suas ramificações nas economias urbanas em uma nebulosa de relações pelas quais o dinheiro da droga circula e impulsiona os mercados e os empreendimentos legais com impactos consideráveis na economia local, para além do que se poderia designar genericamente como operações de lavagem do dinheiro "sujo" 34; seja, no plano de seus modos de territorialização nas periferias urbanas, seu imbricamento no jogo das relações sociais e na lógica da "viração" de todos os dias, que se faz justamente nas fronteiras embaralhadas do legal e ilegal, lícito e ilícito35; seja, ainda, a redefinição dos jogos locais de poder e seus modos de regulação na disputa pela apropriação dessa forma nebulosa de riqueza (entre corrupção, formas
[29] Tomo a expressão de Fresia, Marion. "'Frauder' lorsqu'on est réfugié". Politique Africaine, $\mathrm{n}^{\circ}$ 93, mar., 2004, pp. 63-81. Em seu estudo sobre os inusitados percursos de jovens refugiados nas fronteiras do Senegal e da Mauritânia, a autora levanta questões que têm paralelos interessantíssimos com o que está sendo proposto aqui.

[30] Cf. Tarrius, La remontée des Suds, op.cit.

[31] Cf. Chouvy, Pierre-Arnaud e Aureano, Guilhermo (eds). "Drogue et politique". Cemoti, Cahier d'Études surlaMediterranée Orientale et le Monde Turco-Iranien, $\mathrm{n}^{\circ} 32,2001$.

[32] Cf. Naim, Moises. Ilícito: o ataque da pirataria, da lavagem de dinheiro e do trafico à economia global. Rio de Janeiro: Zahar, 2006.

[33] Ruggiero e South, op.cit.,

[34] Cf. Peraldi. "Economies criminelles et mondes d'affaires à Tanger". Cultures $\mathcal{E}$ Conflits, $\mathrm{n}^{\circ} 68,2007$, pp. 111-126. Ver também Guez, Sabine. “À la frontière du légal et de l'illégal: travail et narcotrafic à Ciudad Juarez (Mexique) et El Paso (États-Unis)". Problèmes d'Amerique Latine, $\mathrm{n}^{\circ}$ 66-67, 2007, pp. 9-20.

[35] Cf. Kokoreff, op. cit. 
[36] Cf. Rivelois, Jean. "Le pouvoir clientéliste local. Une comparaison mexicaine: l'intégration sociale par l'économie souterraine de la drogue". Lusotopie, 1996, pp. 333-42. Ver também Chassagne, Philippe. "Opiacés et routes des Balkans: facteurs géographiques, historiques et politiques du phénomène". Hérodote, $\mathrm{n}^{\circ} 112,1^{\circ}$ trimestre, 2004 .
[37] Cf. Misse, op. cit.; Zaluar, Alba. Integração perversa: pobreza e tráfico de drogas. Rio de Janeiro: FGV Editora, 2004.
[38] Cf. Oliveira, Francisco. "O ornitorrinco". In:Crítica à razão dualista/O ornitorrinco. São Paulo: Boitempo, 2003. de clientelismo, acordos mafiosos, violência aberta ou camuflada) em situações de encolhimento das prerrogativas estatais ou então de perda do monopólio da violência legítima, para lembrar aqui a fórmula famosa de Weber ${ }^{36}$.

Por fim, se a noção de "bazar metropolitano" interessaé sobretudo porque oferece um plano de referência que permite situar (mas sem confundir em um amálgama confuso) os vetores que hoje atravessam e estruturam as dinâmicas urbanas atuais. São eles as mutações do trabalho (e as redes nebulosas de subcontratação) que tornam incertas as diferenças entre trabalho precário, emprego temporário, expedientes de sobrevivência eatividades ilegais - a zona cinzenta em que operam as "mobilidades laterais" dos trabalhadores urbanos nos principais centros metropolitanos da atualidade. São também as formas de circulação de riqueza que se territorializam nas várias modulações do dito mercado informal e do comércio popular proliferante nos centros urbanos por onde circulam bens e produtos de origem duvidosa entre pirataria, contrabando, falsificações ou simplesmente desvio dos circuitos produtivos oficiais. Trata-se ainda do mercado dos bens ilícitos (drogas, sobretudo) também conectados em redes transnacionais, com capilaridades nas dinâmicas urbana e que dependem, assim como outros mercados ilegais, em seus modos de territorialização, dos mercados (também ilegais) de proteção - esses também compõem o "bazar metropolitano" na sua face política ou então crapulosa, para lembrar aqui a discussão proposta por Peraldi.

\section{DINÂMICAS URBANAS REDEFINIDAS}

Bem sabemos que, entre nós, o "bazar metropolitano" não é exatamente uma novidade. Esse trânsito entreo informal eo ilegal, quiçá o ilícito, sempre ocorreu em cidades caracterizadas desde longa data por um expansivo mercado informal, sempre próximo e tangente aos mercados ilícitos que também têm uma história importante de ser, em outro momento, reconstruída ${ }^{37}$. Porém, se há, hoje, a reatualização de uma história de longa duração, há também um deslocamento considerável na ordem das coisas. É também nesse ponto que o "bazar metropolitano" descrito por Ruggiero interessa como referência que permite situar a contemporaneidade e as ressonâncias do que acontece aqui e lá. Isso que sempre foi considerado uma evidência das incompletudes de nossa modernidade, a "exceção do subdesenvolvimento", como diz Chico de Oliveira, projetou-se no núcleo dinâmico de um capitalismo que mobiliza e reproduz o "trabalho sem forma" ${ }^{38}$, ao mesmo tempo em que fez generalizar os circuitos ilegais de uma economia globalizada nas sendas abertas pela liberalização financeira, a abertura dos mercados e encolhimento dos controles 
estatais 39 , em um tal intrincamento entre o oficial e o paralelo, entre o legal e o ilegal, o lícito e o ilícito que essas binaridades perdem sentido e tornam obsoletas as controvérsias clássicas em torno do formal e do informal4o.

Por outro lado, se a situação brasileira tem que servista sob o ângulo dos processos transversais que a atravessam, também é importante averiguar os modos de sua territorialização, em interação com contingências locais, história e tradições herdadas, assimetrias e desigualdades quelhes são próprias. Nesse plano, a referência ao "bazar contemporâneo" também interessa, na medida em que propõe a escala urbana para a descrição de recomposições, redefinições e deslocamentos nas relações entre o informal, o ilegal e o ilícito em suas interações com os circuitos urbanos de circulação de riqueza e as relações de poder inscritas em seus pontos de intersecção ${ }^{41}$.

Será importante verificar o modo como as dinâmicas urbanas são redefinidas por essas novas formas de produção e circulação de riquezas que caracterizam a experiência contemporânea. Trata-se do engendramento de formas urbanas atravessadas por circuitos econômicos em escalas variadas que se superpõem e se entrecruzam nos mercados informais, também eles redefinidos, pois agora conectados a economias transnacionais que mobilizam os trabalhadores e ativam agenciamentos locais informais, também ilegais, para fazer circular bens e mercadorias.

Basta seguir os produtos que circulam nos centros de comércio popular na cidade de São Paulo, com a legião de ambulantes que fazem circular produtos de origens variadas, quase sempre duvidosas, pondo em ação agenciamentos locais e territorializados (verdadeiros dispositivos comerciais) que fazem a articulação entre o informal e os circuitos ilegais das economias transnacionais (contrabando, pirataria, falsificações). São pontos de ancoramento de um capitalismo que, como diz Alain Tarrius, mobiliza os "pobres" como clientes, consumidores e operadores ou passadores que garantem a circulação e a distribuição de mercadorias que, sem esses circuitos nas fronteiras porosas do legal e ilegal, quando não ilícito, não chegariam aos recantos mais pobres das várias regiões do planeta. Disso temos as evidências na expansão mais do que considerável dos mercados de consumo popular, que apresentam uma densidade notável no centro da cidade, mas que se expandem igualmente nos bairros periféricos em mercados locais apoiados em uma trama variada tecida nas fronteiras incertas do informal, do ilegal e do ilícito.

É essa teia de mediações e esse jogo de escalas entrecruzadas que podemos desdobrar a partir de qualquer um desses pontos de venda que se multiplicam nos espaços urbanos e por onde circulam produtos os mais variados: os muito modernos mercados de Cd pirata, produtos falsificados ou então contrabandeados, dos cigarros vindos
[39] A esse respeito, ver Naim, op. cit.

[40] Para essa discussão, tomando como referência a situação dos países africanos, ver Bayart, Jean-François, Ellis, Stephen e Hibou, Béatrice. The criminalization of the State in Africa. Bloomington: Indiana University Press, 1999; Bayart. "Le crime transnational et la formation de l'État".Politique Africaine, Dossier Globalisation et Illicite en Afrique, $\mathrm{n}^{\circ}$ 93, mar., 2004, pp.93-104; Botte, Roger. "Vers un État illégal-légal?". Politique Africaine, $\mathrm{n}^{\circ}$ 93, mar. 2004, pp. 7-21.

[41] Essa é a aposta inscrita nos vários artigos que compõem a coletânea organizada por Kokoreff, Michel, Peraldi, M.e Weinberger, Monique, Economies criminelles et mondes urbains. Paris: PUF, 2007. 
[42] Cf. Freire, Carlos. Trabalho informal e redes de subcontratação: dinâmicas urbanas da indústria de confecções em São Paulo. São Paulo: dissertação de mestrado, FFLCH-USP, 2008 do Paraguai, passando por isqueiros vindos sabe lá de onde, até os eletrônicos que chegam dos contêineres chineses desembarcados no porto de Santos. São uma entre outras tantas fontes de renda para os que agenciam esses pontos de venda, mobilizando redes locais de sociabilidade e mais uma cascata confusa de intermediários por onde circulam produtos cuja origem convém não perguntar, mas que fazem a alegria sobretudo dos mais jovens (mas não só deles) com seus aparelhos de $\mathrm{MP}_{3}$, celulares modernos, aparelhos de som e DVD.

Esses entrecruzamentos entre dinâmicas urbanas e modos de territorialização de circuitos econômicos transnacionais são igualmente perceptíveis nas redes de subcontratação que se expandem, em cascata, em uma zona cinzenta que torna indiscerníveis as diferenças do legal e ilegal, e que são mobilizadas, por exemplo, por uma indústria têxtil em aceleradíssimo processo de integração ao capital globalizado. Tomemos um exemplo, seguindo as pistas da pesquisa de Carlos Freire na cidade de São Paulo42: nos pontos extremos da periferia leste da cidade, o tradicional e hoje renovado trabalho a domicílio. Sob certa perspectiva, exemplo paradigmático da atividade de sobrevivência, própria ao mundo da pobreza com todas as limitações e vulnerabilidades que lhe são definidoras nos pontos de junção entre precariedade e segregação urbana. No entanto, basta seguir o traçado dos produtos para que outra topografia urbana e social seja desenhada. A partir daí é possível desenrolar os fios dos circuitos variados do chamado mercado informal e,em suas conexões, os vários coletivos aí atuantes: os intermediários que fazem a conexão com os pólos globalizados da economia e também com os negócios obscuros de procedência variada; as associações comunitárias ditas filantrópicas que se transformam em agenciadoras das redes locais de subcontratação numa peculiar mistura de apelo solidário, clientelismo jogo de poder nas disputas locais, tudo isso redefinido na medida em que é justamente mobilizado por redes de subcontratação acionadas sabe-se lá por quem e de modo muito obscuro, pois nunca se sabe ao certo de onde vem a encomenda, muito menos quem paga pelo trabalho feito e para aonde vai o produto realizado. Atravessando tudo isso, nos mesmos espaços e nos mesmos territórios, os fluxos da migração clandestina trazem para os fundos da periferia leste os bolivianos, agora personagens conhecidos da paisagem urbana, que vivem e trabalham em condições mais do que penosas, já que em boa medida são cativos dos coreanos que muito freqüentemente agenciam a migração e estão muitíssimo bem instalados no centro da cidade.É dali que saem as encomendas que vão circular pelas redes informais de subcontratação, mobilizando bolivianos e mais boa parte do trabalho a domicílio nessas regiões distantes da cidade, ativando os circuitos da produção têxtil que, no caso da zona leste da cidade, se alimenta da história urbana da região e reatualiza a importância do "centro velho" 
da cidade (Brás, Bom Retiro), ondeestão instaladas as confecções, onde se entrelaçam todos esses fios, abertos e subterrâneos ou clandestinos, e são igualmente urdidas as vinculações com um mercado em aceleradíssimo processo de integração no capital globalizado.

Essas linhas desdobram-se e encontram um ponto (outro ponto) de junção nos lugares de concentração do comércio ambulante, onde todas as situações podem ser encontradas lado a lado, num total embaralhamento do legal e do ilegal, do lícito e do ilícito, do formal e do informal. Ali os produtos circulam por meio de acordos nem sempre fáceis de serem mantidos entre organizações mafiosas, gente ligada ao tráfico de drogas, comerciantes pobres, intermediários dos coreanos (e de outros tantos), além dos fiscais da prefeitura que tentam fazer valer as regulações oficiais, tudo isso misturado com pressões, corrupção, acertos obscuros e histórias de morte. Todo um jogo de atores que atuam nessa zona cinzenta feita de alianças, disputas ou acertos escusos, tudo isso regido por relações de força que liberam uma violência sempre presente, sob formas latentes ou abertas, mas potencialmente devastadoras. Mas é lá mesmo que circulam produtos de procedência conhecida, desconhecida, duvidosa ou simplesmente ilícita, mas também o "excedente", se é que é possível falar nesses termos, das famílias que se viram como podem para bem aproveitar o tempo que lhes sobra entre os ritmos descontínuos e incertos da produção sob encomenda.

Todas essas linhas seentrecruzam nas práticas sociais, no plano das famílias, da economia doméstica e das redes sociais, e aí o jogo social se faz em conexão com outros tantos circuitos que embaralharam ainda mais as fronteiras do legal e do ilegal, do formal e do informal, do lícito e do ilícito. É nesse plano que o varejo da droga encontra seus pontos de ancoramento, se enreda nas tramas urbanas em que os fluxos de dinheiro, de mercadorias, de produtos ilegais e ilícitos se superpõeme se entrelaçam nas práticas sociais e nos circuitos da sociabilidade popular. Por economia de texto, já que o tema exigiria muito mais do que é possível nessas linhas43, é aqui que entram em cena figuras como a prosaica Doralice, com a qual abrimos esse artigo, personagem urbano que, em seus percursos, também nos faz ver o modo como esse imbricamento se conjuga nas tramas da cidade. O fato é que indivíduos e suas famílias transitam nessas tênues fronteiras do legal e do legal, sabem muito bem lidar com os códigos de ambos os lados, sabem jogar com as diversas identidades que remetem a esses diversos universos superpostos e embaralhados nas coisas da vida. Sabem, sobretudo, exercitar essa especial "arte do contornamento" para evitar os riscos alojados justamente nas dobras dessas fronteiras porosas: a violência da polícia, sempre presente nesses percursos, e também a eventualidade de algum desarranjo nos acertos instáveis com os empresários do ilícito, e não apenas o tráfico de drogas ${ }^{44}$.
[43] Permito-me remeter ao nosso artigo em que essas questões foram tratadas com base em pesquisa realizada em um bairro da periferia paulista. Cf. Telles e Hirata, op. cit.
[44] Desenvolvi essas questões em Telles, "Transitando na linha de sombra, tecendo as tramas da cidade". In: Oliveira, Francisco e Rizek, Cibele (orgs.). A era da indeterminação. São Paulo: Boitempo, 2007. 
[45] Foucault, Michel. Vigiar e punir. Petrópolis: Vozes, 2006, p. 227.
[46] Misse. "Mercados ilegais, redes de proteção e organização local do crime". Revista Estudos Avançados da USP, vol. 21, nº 61, 2007, pp. 139-158.

[47] Questão especialmente enfatizada por Kokoreff em suas pesquisas sobre os "mundos da droga" no contexto francês. Cf. Kokoreff, op. cit. Entre nós, cf. Misse, "Mercados ilegais...", op. cit.

\section{UMA NOVA GESTÃO DAS ILEGALIDADES?}

A redefinição das relações entre o informal, o ilegal e o ilícito, de alguma forma expressa na noção hoje revisitada de "economia de bazar", poderia ser vista sob o ângulo de um deslocamento das formas de "gestão dos ilegalismos". Lembremos: ao cunhar essa noção em Vigiar e punir (1975), Foucault desloca a discussão da tautológica e estéril binaridade legal-ilegal, trazendo para o centro da investigação os modos como as leis operam, não para coibir ou suprimir os ilegalismos, mas para diferenciá-los internamente, "riscar os limites de tolerância, dar terreno para alguns, fazer pressão sobre outros, excluir uma parte, tornar útil outra, neutralizar estes, tirar proveito daqueles" 45 . Na passagem do século XVIII para o século XIX, tratavase de lidar com uma "nova economia política dos ilegalismos populares", uma outra distribuição dos ilegalismos que acompanhava as novas formas de produção e circulação de riquezas (a economia urbano-industrial), seus modos de apropriação (o instituto jurídico da propriedade privada) e as polarizações conflituosas (e explosivas) de classes que desfaziam as cumplicidades anteriores e se desdobravam nas "multidões confusas" que era preciso então desfazer e ordenar sob a lógica dos dispositivos disciplinares então em formação. Não seria arriscado dizer que, nesta outra virada dos tempos, do século XX para o XXI, há um deslocamentos considerável na "economia interna dos ilegalismos populares", acompanhando as atuais reconfigurações do capitalismo contemporâneo.É o que se pode ler, em filigrana, nas várias pesquisas comentadas ao longo deste texto. É isso o que está igualmente cifrado nas clivagens nem sempre muito claras entre a transgressão que se opera no âmbito da economia informal e a que se define a atividades ilegais ou propriamente criminosas, como o tráfico de drogas.

Seja como for, se é de interesse compreender os novos ilegalismos urbanos, não se poderá descartar do campo da investigação a face política do "bazar metropolitano", seja no registro dos agenciamentos políticos que se fazem nas dobraduras do legal e do ilegal — os mercados de proteção-extorsão que, como enfatiza Michel Misse, são mais ou menos ferozes e violentos conforme o grau de incriminação dessas atividades ${ }^{46}$ - seja no registro do modo como os mercados ilegais e ilícitos se redefinem, se deslocam, se reorganizam conforme alteram as práticas de controle, punição, repressão, bem como as categorizações jurídico-policiais que comandam seus modos de tipificação47.

$\mathrm{Na}$ verdade, isso definiria um amplo programa de investigação. Porém, essas breves sugestões têm aqui o sentido de chamar a atenção para o fato de que as redefinições das formas de controle afetam esses trabalhadores urbanos que transitam nas fronteiras porosas do legal 

indivíduos com passagens pelos dispositivos judiciais-carcerários são cada vez mais presentes no cenário urbano atual, aqui e alhures ${ }^{48}$. A questão está na pauta dos debates atuais49. Impossível enfrentá-la nos limites desse texto, pois envolve outros tantos aspectos do cenário contemporâneo.

Mas se corremos o risco de passar de modo tão ligeiro por uma questão dessa envergadura é porque não é possível evitá-la, menos por conta da lógica interna de um argumento e mais, muito mais, por uma imposição de evidências de que não se pode contornar. Faz parte do diário de campo de qualquer pesquisador que circule pelas periferias da cidade a constatação de queé, hoje, quase impossível encontrar uma família que não tenha contato e familiaridade, direta ou indireta (conhecidos, vizinhos, parentes) com a experiência do encarceramento. Isso levanta a pergunta sobre o modo como essa experiência afeta práticas cotidianas e os modos de organização da vida familiar (apoios, visitas, advogados, busca de recursos e solidariedades etc.) e, junto com isso, a ativação de redes sociais que passam, também elas, por essas fronteiras porosas do legal-ilegal, lícito-ilícito, para mobilizar recursos, suportes, bens e informações de que depende a vida dos parentes aprisionados. Em outras palavras, o dispositivo carcerário compõe atualmente uma referência urbana, redesenha os circuitos da cidadee em torno dele, nas fronteiras também porosas do fora e dentro de seus muros, há toda uma trama de relações que vai sendo tecida em um jogo social variado que termina por desativar a binaridade ordemdesordem pela qual os dispositivos disciplinares (aqui, novamente Foucault) recortaram e formalizaram as transgressões ${ }^{50}$.

O ex-presidiário é hoje um personagem urbano presente (ecadavez mais presente) nas tramas sociais do "bazar metropolitano": seja como operador dos vários ilegalismos da economia urbanas; seja como componente importante nessa espécie de reprodução ampliada dos mercados ilícitos (e da criminalidade urbana) na própria medida em que se encontra cativo de formas de controle que o mantém no circuito fechado da "delinqüência" - como diz Foucault, uma forma subordinada dos ilegalismos populares; seja ainda porque está presente, o tempo todo, nos agenciamentos da vida cotidiana e nas redes sociais que passam pela família, pelas relações de vizinhança e todas as cumplicidades tecidas no jogo das reciprocidades populares.

Mas é nesse ponto que se pode também reatar com a questão proposta no início deste artigo, o plano de atualidade que atravessa essas realidades, em ressonância com o que vem acontecendo em outros lugares. Temos aqui, talvez, outra pista a ser seguida para entender

[48] Em todos os lugares, vem se dando o que Garland chama de "encarceramento em massa". Vale a citação: “[Nos Estados Unidos] o encarceramento tornou-se uma instituição social que estrutura as experiências de grupos sociais inteiros. Tornouse parte do processo de socialização. Cada família, cada domicílio, cada indivíduo em sua vizinhança tem uma experiência pessoal e direta com a prisão - por meio da esposa, de um filho, de um parente, de um vizinho, de um amigo. Encarceramento que deixou de ser o destino de um punhado de indivíduos criminosos, e torna-se uma instituição que ganha forma para amplos setores da população. [...] Temos, hoje, verdadeiras bibliotecas de pesquisas em criminologia sobre o impacto da prisão sobre os indivíduos encarcerados, mas quase nada sobre o seu impacto social nas comunidades e suas vizinhanças" (Garland, David. Mass imprisionment: social causes and consequences. Londres/Thousand Oaks, Calif.: Sage, 2001).

[49] Loic Wacquant e David Garland são referência obrigatória nessa discussão. De Wacquant, ver "O lugar da prisão na nova administração da pobreza". Novos Estudos Cebrap, ${ }^{\circ}$ 80, mar., 2008. De Garland, ver The culture of control: crime and social order in contemporary society. Chicago, The University of Chicago Press, 2001, e também "As contradições da 'sociedade punitiva': o caso britânico". Revista de Sociologia e Política, $\mathrm{n}^{\circ} 13$, nov., 1999, pp. 59-80.

[50] A questões discutidas por Manuela Cunha no contexto português têm paralelos notáveis com as situações encontradas nas periferias paulistas. Cf. Cunha, Manuela. "Entre o bairro e a prisão: tráfico e trajectos". Lisboa: Fim de Século, 2002. 
Recebido para publicação

em3 de março de 2009 .

\section{NOVOS ESTUDOS}

CEBRAP

84 , julho 2009

pp. 153-173 alguns dos processos transversais que atingem as sociedades atuais e que, nesse caso, remetem ao endurecimento penal e das formas de controle. Esse é o outro lado do deslocamento das fronteiras do formal-informal, legal-ilegal, lícito-ilícito, deslocamento que precisaria ser analisado em relação às mudanças na "gestão diferencial dos ilegalismos". Isso supõe colocar no foco da discussão os modos de incriminação e a redefinição, como sugere Garland, das formas de controle na sociedade pós-disciplinar ou, como propõe Wacquant, o lugar redefinido da prisão na sociedade pós-fordista, como forma de gestão da pobreza, compondo e interagindo com dinâmicas urbanas nas quais também se atualizam e se redefinem traços persistentes de nossa história.

VERA DA SILVA TELLES é socióloga e professora do Departamento de Sociologia da USP. 